\title{
Professor Shigekoto Kaihara
}

Professor Shigekoto Kaihara, Vice-President of International University of Health and Welfare passed away of the thoracic aorta aneurysm in the midst of the faculty meeting on January 12, 2011.

He was born in Hakusan, Tokyo in 1937. He moved to Dailen, China soon after his birth due to his father's work, He came back to Japan at the age of eleven. He proceeded to the middle school operated by Ochanomizu University, and then to Tokyo Metropolitan Hibiya High School, concentrating on his schoolwork and Japanese-style swimming.

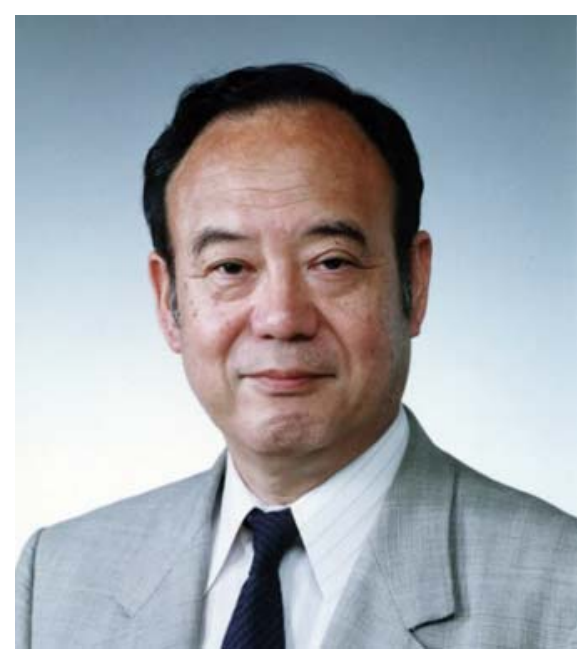

In 1955 he entered the University of Tokyo, being certified by ECFMG (the U.S. Educational Commission for Foreign Medical Graduates) during the period of his enrollment in school. After graduation in 1961, he received clinical training in the U.S. Forces Tachikawa Hospital. Then, he acquired a doctor's degree through his investigation into nuclear medicine at the University of Tokyo graduate school medical faculty. In 1966, he went to the U.S. to study at Johns Hopkins Hospital. After returning to the University of Tokyo, he became the 2nd internal medicine assistant in 1969, a lecturer in 1974, and an assistant professor in 1975. From this time, he had already begun work on medical informatics, and in 1978 he became the director of the Information Processing Division of the attached hospital.
Through 1980s, he investigated the medical consultation system using artificial intelligence and also trained young researchers. He held several international symposiums in the U.S. and Germany. Those researchers trained by him exercise leadership now in medical informatics and other related fields.

In Japan, he was a pioneering authority of medical informatics. The activities about medical informatics in the 70 's were addressed separately by Japan Society of Medical Electronics and Biological Engineering (now, Japanese Society for Medical and Biological Engineering), Information Processing Society of Japan, etc. Those activities were integrated by him when MEDINFO 80 (World Congress on Medical Informatics) was held in Tokyo. In the following year of 1981, he organized the 1st Joint Conferenceon Medical and Biological Informatics (now, Joint Conference on Medical Informatics, operated by Japan Association for Medical Informatics), paving the way to establishment of Japan Association for Medical Informatics.

He was a person of considerable insight and contributed to the work of several ministries. They include, among others, the ministry of education (Science Council member (two times), High Education Bureau science advisor), the ministry of health (Council for those engaged in Medical Service Committee member, Independent Administrative Agency Evaluation Committee member, Social Security Council member) and the ministry of economy and trade (Data Processing Promotion Council member, Healthcare Industry Workshop member).

Internationally, he was an editor in chief of the above-mentioned MEDINFO 80 (Tokyo), a chairman of the International Medical Informatics Association (IMIA) from 1986 to 1989 , and a program committee chairman of MEDINFO 95 (Vancouver). In 1998, he was recommended for ACMI fellow by American Medical Informatics Association. Especially, during his chairmanship, he successfully held MEDINFO 89 at two venues, Beijing and Singapore, despite the dif- ficult international situation. This was the remarkable event in the IMIA history.

After retiring from office at the University of Tokyo in 1996 and becoming an emeritus professor, he became director of National Okura Hospital (later integrated as National Center for Child Health and Development). He installed a network circuit even toeach sickbed, and realized "Patient Participation". Simultaneously, within the same site, he built the facility called Donald McDonald House for parents of sick children for the first time in Japan.

After that, he was committed to the doctrine that "improvement of medical care in Japan requires better education of co-medical staff" and became VicePresident of International University of Health and Welfare in 2001 to educate nurses, clinical laboratory technologists, care workers and medical informatics engineers. In order to reflect this doctrine, he became the Vice-Chairman of the 28th General Assembly of Japanese Association of Medical Sciences and opened the event even to general public other than medical doctors.

His wife, Hisayo, is also a medical doctor, who was one of his classmates in high school and the University faculty of medicine. They spent the vacation every summer in the cottage located in Karuizawa, one of famous summer resorts in Japan. They invited students and young researchers, playing tennis, serving their favorite roast beef dishes and creating always the homely atmosphere. They had two daughters. Recently he had been a goodnatured old man and liked to frequent Sendai City, $300 \mathrm{~km}$ away from Tokyo, to meet his grandchild living there.

In 1994, he contributed an article to IryoJohogaku (Medical Informatics), which is titled "Medical informatics in Japan - Challenge in the coming five years". His vision has been only partially embodied so far. We are now determined to remember his vision and his contribution to society through medical informatics.

Kazuhiko Ohe and Michio Kimura 
January 15, 2011

Letter of Condolence

I would like extend my deepest sympathies to Dr. Kaihara's family and to the members of the Japan Association of Medical Informatics.

I had the honor and the pleasure to know Dr. Kaihara since the 60's when I visited the second department of internal medicine at Tokyo University hospital. I have had the greatest respect for him ever since because he was such a great mentor as well as a wonderful friend.

Dr. Kaihara introduced me to medical informatics by recommending me as a corresponding member of the International Medical Informatics Association, which led me to found the Korean Society of Medical Informatics in 1987. When I hosted an academic conference on the founding day of the Korean Society of Medical Informatics, he came to Seoul to congratulate us for the inauguration of the Society and gave a wonderful keynote speech on medical informatics to our Korean colleagues who were not sure of what medical informatics was all about. Then, he invited me to the IMIA GA held in Singapore in 1989 and helped the Korean Society of Medical Informatics become an official member of the IMIA on the site. Later, he guided us to bid for Medinfo 1998 successfully. He even brought Japanese colleagues to Korea to hold the annual conference of the JMIA because he wanted Medinfo 1998 to be a success.

It is a very sad to moment to say goodbye to my wonderful mentor and dear friend. I am sure we all will miss him greatly. Please let me know whether there is anything for me or the Korean Society of Medical Informatics to do to help during this difficult time. I want to you know that all of you are in my thoughts and prayers.

Thank you all and good bye Dr. Kaihara.

\section{Chang Soon Koh}

Past Chair

Korean Society of Medical Informatics
After the untimely decease of Dr. Shigekoto Kaihara I wrote on January 13th, 2011 a personal letter to his wife Mrs Kaihara, whom I had the honor to meet several times, also twice in their home in Tokyo. Although this letter does not primarily concern the many and impressive contributions of Kai to the field of (bio)medical informatics, it expresses my warm feelings for him as a person. Therefore, I would like to contribute in the same personal way to the different writings in memory of my good friend Kai. The letter was phrased as follows:

\section{Dear Mrs. Kaihara and family,}

It is with extremely great sadness that I write this letter to you, having been informed about Kai's decease. Kai's death must be a great loss to you all, but also to the whole community of medical informatics. Kai's too early passing reminds us of our fragile human life. Kai was just one year older than I am, so in that respect his passing also makes a deep impression.

I had the privilege of knowing Kai for almost 33 years. The first time we met was in 1978 at a conference in Osaka, but during the years after that event there were numerous meetings all over the world. For instance, I still remember very vividly one other year that I visited Tokyo, it must have been in 1981, that I also met you and your then still young - lovely daughters in your home in Tokyo. They played the flute for us during that visit. The second time that I visited you in your home was in 1998 when I was invited to make a tour in Japan to assess the current state of affairs in medical informatics in your country. I very well remember the long conversations I had with you and Kai on your great interest in persons with a mental handicap. After our visit we also had some correspondence on these issues.

At all times that Kai and I have met there was immediately a good understanding. In 2007 we even had a joint publication, as former IMIA presidents, together with Marion Ball, which was published in 'Methods'. My memories of Kai are extremely positive, him being always very friendly and interested in everything, also widely outside medical informatics.

Especially the conversations we had in your home had a very personal character, like me Kai and you being very interested in the meaning of human life. I even got the privilege going with him to the special place in your home where you honor your ancestors. It was proof of his and your openness and friendliness. He was also a perfect host and enjoyed, like me, a glass of good wine.

Dear Mrs. Kaihara, please do consider the sentences I wrote as a sign of deep respect for my good friend Shigekoto Kaihara. I regret that the distance is too large to pay attention in person at the last farewell of Kai, but my high regard is no less. Of course, whenever you or your daughters would visit Europe and in particular The Netherlands, do not hesitate to let me know so that my wife An and me would have a great pleasure receiving you.

With kindest regards,

Jan H. van Bemmel

Professor of Medical Informatics IMIA President 1998-2001 